SHORT REPORT

\title{
Increased prescribing trends of paediatric psychotropic medications
}

\author{
I C K Wong, M L Murray, D Camilleri-Novak, P Stephens
}

Arch Dis Child 2004;89:1131-1132. doi: 10.1136/adc.2004.050468

Psychotropic medication use by children in the USA has increased. We used the IMS MIDAS Prescribing Insights to examine prescribing trends in nine countries between the years 2000 and 2002. Trends in seven countries rose significantly from year 2000 to 2002; the UK had the highest increase $(68 \%)$.

$\mathrm{S}$ tudies in the USA have shown that the use of psychotropic medications has increased considerably in recent years. ${ }^{1}$ We have previously reported a similar trend in the UK. ${ }^{2}$ However, there is little information on the prescribing trends in other countries; we do not know whether this is a global trend or a trend in English speaking countries. For the above reason, we used the IMS MIDAS Prescribing Insights to examine the prescribing trend of psychotropic medications in children in nine countries between the years 2000 and 2002.

\section{METHODS}

Children are defined as under 18 years old. The psychotropic medications investigated include antidepressants, stimulants, antipsychotics, benzodiazepines, and other anxiolytics.

IMS MIDAS Prescribing Insights contains the prescribing data from different countries. We obtained the paediatric psychotropic prescription data in the UK and three other European countries with the largest markets for these medications (France, Germany, and Spain), three South American countries with the largest markets for these medications (Argentina, Brazil, and Mexico) and North America (Canada and the USA).
IMS MIDAS Prescribing Insights is an audit drawn from a representative sample of medical practitioners in each country; table I summarises the details of data collection of each country. The prescribing data of sampled doctors were then adjusted according to the stratifications, and a projected national total of prescriptions data per year and 95.5\% confidence intervals were calculated for each country. The within country differences of the data between years 2000 and 2002 were compared for significance.

\section{RESULTS}

Figure 1 shows that the number of psychotropic prescriptions for children has risen between the years 2000 and 2002 in all nine countries, and seven have shown a significant increase. The UK has the highest percentage increase $(68 \%)$; the lowest was Germany (13\%).

\section{DISCUSSION}

The results suggest that the increase in psychotropic prescribing in children is not only confined in the USA and UK but is also evident in other countries. The increase probably represents the improved recognition of paediatric psychopathology; there is also a concern that drugs are being used to replace non-drug treatments. ${ }^{3}$ However, there is insufficient research to confirm or refute the above suggestions. There are limitations to our data, especially as there is no information on the average prescription duration by drug or frequency, which may differ between years due to changes in prescribing practice. However, the observed increase in so many countries should raise concern, as little research has been conducted in children to study the effects of most psychotropic medications.

Table 1 Method of data collection in each country

\begin{tabular}{|c|c|c|c|}
\hline Countries by continent & $\begin{array}{l}\text { No. of doctors involved } \\
\text { in data collection }\end{array}$ & Stratification of sampling & Reporting time \\
\hline \multicolumn{4}{|l|}{ Europe } \\
\hline France & 835 & $\begin{array}{l}\text { Region, age of doctor, community size, activity } \\
\text { level, sex of doctor, environment (typology of areas) }\end{array}$ & 7 consecutive days per quarter \\
\hline Germany & 2806 & Region, specialty, community size & 7 consecutive days per quarter \\
\hline Spain & 850 & Region, specialty, community size & 7 consecutive days per quarter \\
\hline UK & 500 & Region, year of doctor qualification & $\begin{array}{l}\text { Daily throughout year } \\
\text { (computerised GP records) }\end{array}$ \\
\hline \multicolumn{4}{|l|}{ South America } \\
\hline Argentina & 470 & Region, specialty & 7 consecutive days per quarter \\
\hline Brazil & 1155 & Region, specialty & 5 consecutive days \\
\hline Mexico & 1050 & Region, specialty & $\begin{array}{l}\text { Minimum of } 4 \text { consecutive days and } \\
\text { maximum of } 6 \text { per quarter }\end{array}$ \\
\hline \multicolumn{4}{|l|}{ North America } \\
\hline USA & $\begin{array}{l}1227 \text { physicians report } \\
\text { per month; } 3678 \text { physicians } \\
\text { report per quarter }\end{array}$ & Two staged stratified cluster, randomly drawn & 2 consecutive days per quarter \\
\hline Canada & 652 & Region, specialty & 2 consecutive days per quarter \\
\hline
\end{tabular}




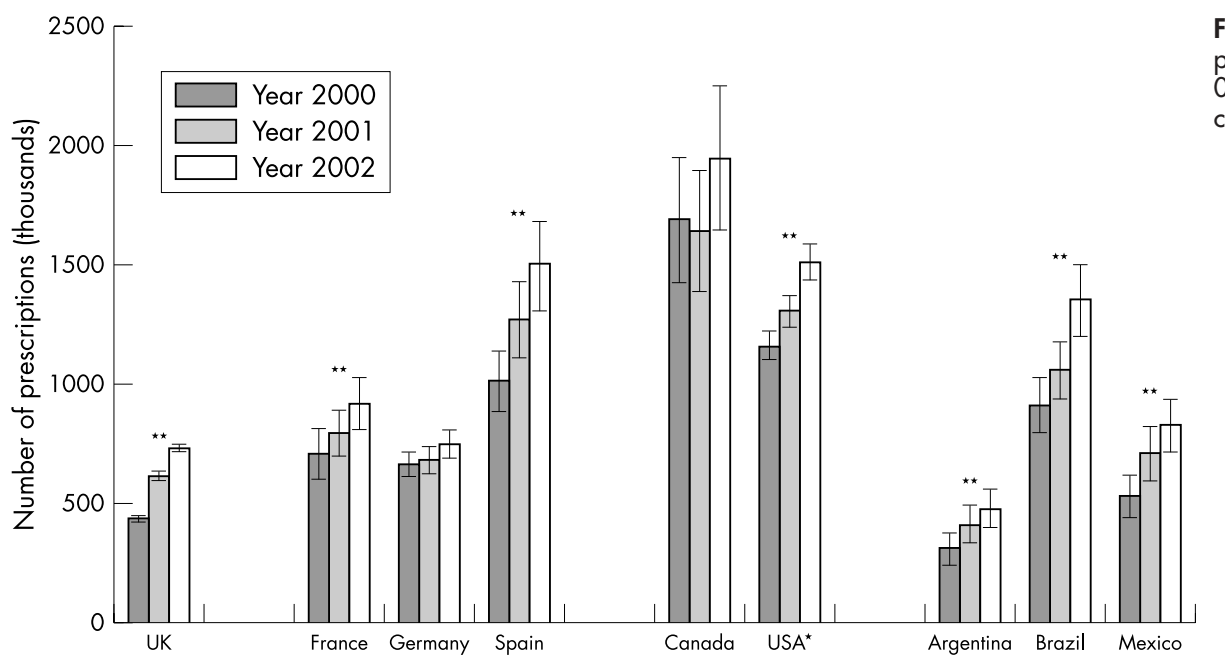

Figure 1 Psychotropic medication prescriptions given to patients aged $0-17$ years by country and year $(95.5 \%$ confidence intervals shown).

* USA data is by hundred thousand prescriptions

** Statisically different between the years 2000 and 2002

The recent recommendation by the Medicines and Healthcare products Regulatory Agency to withdraw selective serotonin inhibitors (SSRIs) from the treatment of paediatric depressive disorders ${ }^{4}$ should serve as a lesson to all of us. The percentage of SSRI prescriptions from all antidepressants prescriptions issued to children and adolescents in the UK increased considerably between 1992 and 2001; it is probable that the rationale for drug choice is not based on the research evidence in children, but based on the evidence in adults. This highlights an important point which paediatric clinical pharmacologists and pharmacists always advocate-."children are not small adults".

Certainly we need more well designed clinical trials to investigate the safety and efficacy of psychotropic medications in children; it is also necessary to study how and why these medications are being prescribed, through the application of pharmacoepidemiology. We believe the use of psychotropic medications in children is a global public health issue, which should be studied in partnership with pharmaceutical companies, governments, and researchers to grow and expand the evidence base for their use in children. ${ }^{6}$ Children should not be deprived of safe and efficacious treatments.

\section{ACKNOWLEDGEMENTS}

IW's post is funded by the Department of Health Public Health Career Scientist Award. We thank IMS for providing the data.

\section{Authors' affiliations}

I C K Wong, M L Murray, D Camilleri-Novak, Centre for Paediatric Pharmacy Research, School of Pharmacy and the Institute of Child Health, University of London, UK

P Stephens, VP Public Health Affairs Europe, IMS Health, London, UK

Correspondence to: Dr I C K Wong, Centre for Paediatric Pharmacy Research, The School of Pharmacy, University of London, 29-39 Brunswick Square, London WCIN IAX, UK; ian.wong@ulsop.ac.uk

Accepted 19 February 2004

\section{REFERENCES}

1 Zito JM, Safer DJ, DosReis S, et al. Psychotropic practice patterns for youth: a 10-year perspective. Arch Pediatr Adolesc Med 2003;157:17-25.

2 Wong ICK, Camilleri-Novak D, Stephens P. Rise in psychotropic drug prescribing in children in the UK- an urgent public health issue. Drug Safety 2003;26:1117-18.

3 Wiznitzer $M$, Findling RL. Why do psychiatric drug research in children? Lancet 2003;361:1147-8.

4 Anon. Selective serotonin reuptake inhibitors (SSRIs): overview of regulatory status and CSM advice relating to major depressive disorder (MDD) in children and adolescents including a summary of available safety and efficacy data. http://medicines.mhra.gov.uk/ourwork/monitorsafequalmed/ safetymessages/ssrioverview_101203.htm. Accessed 23 December, 2003.

5 Murray ML, de Vries CS, Wong ICK. Prescribing trends of antidepressants in children and adolescents. Electronic BMJ 5 January 2004. http:// bmi.bmijournals.com/cgi/eletters/328/7430/3\#45608. Accessed 5 January 2004.

6 Wong IC, Sweis D, Cope J, et al. Children medicines research in the UK-how to move forward? Drug Safety 2003;26:529-37. 


\section{PostScript}

\section{LETTERS}

\section{Expert witnesses: opinion and dogma are pitfalls in medical journalism as well as in reports}

Professor David's leading article ${ }^{1}$ provides a welcome summary of the Code of Guidance for Expert Witnesses in Family Proceedings. All paediatricians who undertake this type of work should be familiar with the Code of Guidance and have due regard to it. However, Professor David also goes on to express some highly personal opinions which, while forcefully argued, are unreferenced and not evidence based. The most obvious example in the article is Professor David's views on interviewing the parents or carers. He comments that "a paediatrician who does not attempt to interview the parents risks being criticised for by-passing the usual routines and failing to consider all aspects of the case". He goes on to say that paediatricians willing to make a confident diagnosis of abuse without ever meeting the parents risk making parents exceptionally aggrieved, alluding to recent press publicity.

The undersigned are all experienced in the field of child protection and between us have considerable experience of expert witness work. In our experience, a substantial proportion of Expert Witness Reports are prepared on the basis of a paper review. This has hitherto been regarded as perfectly sound medical practice, which is not explicitly discouraged in any of the published Expert Witness guidance. We would suggest that Professor David's views should not be accepted unquestioningly, and that this issue should be debated openly.

It is undeniable that treating paediatricians need to take a good history from parents, carers or others, especially where child abuse is being considered in the differential diagnosis. The situation is different, however, for an Expert Witness who assesses the case many months after the parents have been confronted with the initial concerns about child abuse. The parents are likely to have had many opportunities to discuss their case and rehearse their history; for example in case conferences, meetings of professionals, and with their lawyers. Usually they will have produced detailed witness statements in connection with civil and/or criminal proceedings. Interviewing carers in this context is not something which paediatric training fully prepares you for, and even experienced paediatricians may have little experience of this. There are significant risks:

(1) Parents, whether innocent or not, will naturally attempt to idealise their histories and portray themselves or other carers in a favourable light. Guilty carers are likely to be untruthful. It is therefore impossible for the paediatrician to know how much weight to attach to the history given by the carer at this point in time. This poses dual risks: paediatricians may become prejudiced against an innocent carer if they perceive them as unreliable; or conversely, they may be "taken in" by a guilty carer who has distorted the history. This can result in the paediatrician being drawn inappropriately into advocating for the carer and failing to be objective about the other medical evidence. It may even result in the paediatrician meeting with the carers, deciding whether they feel that they are telling the truth or not, and then inappropriately interpreting the medical evidence in a way that supports that view. We must not forget that the paediatrician's prime role is to consider whether the child has suffered harm, not to attribute guilt.

(2) Given the long delay between the suspected abuse event and the involvement of the Expert Witness, there is a risk that perfectly innocent errors may creep into the history provided by the carers. There is a risk that the doctor or the court would be prejudiced against the parents in this situation.

(3) There is a further risk for the unwary in potentially becoming prejudiced against parents who have mental health problems, learning difficulties, unusual personalities, or strange affect. This is also to be guarded against, as it is essential for paediatricians to remain objective.

(4) The Expert Witness Guidance specifically forbids paediatricians to seek to resolve disputed issues of fact in their reports. There is a risk that in interviewing the family and generating new information the paediatrician may be drawn into this particular trap.

(5) In some cases there may be a risk of physical harm or intimidation of the Expert Witness. Often we are invited to meet with the family in their own home and without chaperones. This also leaves doctors vulnerable to false accusations concerning their behaviour in interviews. The carers may try to challenge or "cross-examine" the doctor at interview. Doctors need to consider carefully their own health and safety in these circumstances.

(6) The parents may misinterpret, misrepresent or take "false hope" from things that the paediatrician has said to them, or may press for a provisional opinion on the case, which of course should not be given.

(7) Not infrequently, parents or their advocates are suspicious about the paediatrician's motive in wanting to interview the family, even when the doctor is jointly instructed and acting in a completely neutral capacity. They may insist on the interview being recorded and transcribed, which adds delay and expense. If the interview is not recorded the carer may later deny something that they said to the paediatrician if it is unhelpful to their case.

(8) Given that the courts are experiencing extreme difficulty in recruiting Expert Witnesses, adding a further obligatory interview, regardless of its relevance, may deter paediatricians even further from taking on cases.

(9) The new Protocol for Family Law cases was introduced to avoid delay in proceedings and a requirement to interview carers in all cases would inevitably add delay.
(10) Parents often find interviews such as this very stressful. This is only justified if there is clear benefit.

(11) Finally, Professor David's views imply that avoidance of parental upset is a priority. It is to be expected that parents will be upset about the diagnosis of abuse, particularly if they are implicated. However, there is no evidence of which we are aware to suggest that the parents will be less upset, or less likely to complain, if the paediatrician meets with them.

Last year, the President of the Royal College of Paediatrics and Child Health drew attention to an "orchestrated campaign" against paediatricians involved in child protection. Certain well known campaigners, accused parents, and journalists often refer to the fact that a Paediatric Expert Witness had not met the family before coming to a diagnosis, in an attempt to discredit them. In this context, the idea that interviews with parents or carers should be conducted purely to appease them and reduce the likelihood of them complaining is highly controversial and there is no reason to believe that goal would be achieved. Where complaints are received, for example by an NHS Trust or the GMC, it is important that the doctor's performance is judged on the basis of currently accepted and "reasonable" medical practice, and that the opinions of those making these judgements are not influenced by skilfully argued, but personal and controversial views such as those expressed by Professor David.

In some cases, of course the Expert Witness will wish to meet with the carers before coming to a diagnosis. We would not argue that it is wrong to do so subject to the cautions mentioned above, but it should not be obligatory as suggested by Professor David. Ultimately the more objective evidence is contained in the medical records. A careful review of this basic information is often needed before deciding whether to take a further history from the parents. Whether or not the parents or carers have been interviewed should not be regarded as a measure of the quality of the report, and there are many occasions when reports based on paper reviews have been highly commended by courts. In each case paediatricians need to carefully weigh up the pros and cons of interviewing the carers and justify their actions.

Professor David quite correctly entreats all paediatricians to consider both sides of the argument, acknowledge where opinions are controversial or open to challenge, and present material that does not support the Expert's opinion as well as that which does. He also points out that non-medical professionals such as lawyers and judges may overinterpret medical theories. These cautions are well made, but we would suggest that they should also apply to controversial opinions expressed in the medical literature, particularly where they relate to Expert Witness work and could have serious unwanted consequences if they were to pass without comment into medical or judicial dogma. 
M Crawford, P Davis, J Herbison, J Mok, A Mott, H Payne, R Postlethwaite, J Price, M Samuels, J Sibert, J Sills, N Speight

Correspondence to: Dr P Davis, Consultant Paediatrician, Cardiff and Vale NHS Trust, Lansdowne Hospital, Sanatorium Road, Canton, Cardiff, South Glamorgan CF11 8UL, UK : paul.davis@cardiffandvale.wales.nhs.uk

Competing interests: none declared

\section{Reference}

1 David TJ. Avoidable pitfalls when writing medical reports for court proceedings in cases of suspected child abuse. Arch Dis Child 2004:89:799-804.

\section{Reply by Prof. Adam Finn}

\section{Taking a history}

In reading this piece and the published response concerning the merits of personal interviews in child protection cases, I was struck by the sentence introducing the topic which reads: "Most paediatricians would not dream of giving a clinical opinion without taking a history".

Accordingly this week I kept a diary of clinical opinions given. It was a quiet week "off service"-there were only 47: 24 on rounds, 9 in clinic, and 14 by phone, letter, or email. Among these, I met the child and parents and exchanged words with them in only 10. I took a history myself in only 7 . I do infectious diseases and immunology, not child protection, but I reckon this is how consultants work in all areas.

A Finn

Institute of Child Health, UBHT Education Centre, Level 6, Upper Maudlin St, Bristol BS2 8AE, UK; Adam.Finn@bristol.ac.uk

\section{Reply by Dr John C Furness}

\section{Should expert witnesses interview parents?}

Professor David's article ${ }^{1}$ was in the main a helpful guide to those involved in this specialised work. I wonder how many of the readers are involved in this sort of work?

As a recently qualified general paediatrician I was surprised to read his recommendation that expert witnesses should interview the family. In the few child protection cases that I have been involved in as a witness to the fact, colleagues acting as expert witnesses have not interviewed the family. They have restricted themselves to their expert opinions on specific questions of medical knowledge that the legal teams have felt would be helpful to clarify. I read that other expert witnesses agree. ${ }^{2}$

I was also surprised to read Professor David's views without a response from those who have differing opinions, especially as he is intimately involved in Professor Southall's controversial General Medical Council hearing. I do trust that you will uphold the essential principle of good journalism and allow an open debate on this issue with equal prominence to differing views.

J C Furness Locum Consultant Paediatrician, County Durham and Dralington Acute Hospitals NHS Trust; furgo@doctors.org.uk

\section{References}

1 David TJ. Avoidable piffalls when writing medical reports for court proceedings in cases of suspected child abuse. Arch Dis Child 2004;89:799-804.

2 Crawford M, Davis PM, Herbison J, et al. Expert witnesses: opinion and dogma are piffalls in medical journalism as well as in reports. Arch Dis Child 2005;90:218-9.

\section{BOOK REVIEW}

\section{Medical management of AIDS in children}

Edited by William T Shearer, I Celine Hanson. Saunders, 2003, £33.99 (hardcover), pp 434. ISBN 0-7216-8284-7

Where would you get advice on how to manage a child with HIV? From a textbook like this, from the internet, or would you phone-a-friend? Paediatricians in the UK are increasingly likely to see children infected with, or affected by, HIV. Reasons for this include an increasing number of children with HIV and antenatal screening for HIV, which is identifying increasing numbers of infants at risk of mother to child infection. Most of these children will live in the London area, but $25 \%$ are now living in other parts of the UK. Paediatricians thus need information to help them manage these children. This book will provide some useful background information on HIV and about its specific complications. However it may be less valuable in managing children presenting acutely to hospital.

The three commonest reasons for paediatricians calling me for advice about HIV are: initial diagnosis and treatment; indications for antiretroviral therapy; and management of infants born to HIV positive mothers.

\section{Diagnosis and initial treatment}

This book contains little information about the issues involved in testing children for HIV, such as consent and confidentiality. These are probably outside the scope of this book, but essential for paediatricians to understand. These issues are well covered by a document on the Children's HIV Association of UK and Ireland (CHIVA) website (www.bhiva.org/chiva).

Children with HIV may present with a variety of other infections. The chapter on infectious complications of HIV covers many of these. However, again the information on managing children with HIV with fever, respiratory illness, or diarrhoea on the CHIVA website will be of more immediate use to paediatricians.

\section{Antiretrovirals}

When to start antiretrovirals and what drugs to start remains controversial. The increasing number of drugs available will make any textbook out of date, almost as soon as it is published. This is probably the case here where newer agents, like tenofovir, are not mentioned. This book also reflects the American view that almost all children with HIV should be on anti-retroviral treatment. The European view of more selective treatment and more up to date information on the drugs available is available from the Paediatric European Network for Treatment of AIDS (PENTA), available at www.ctu. mrc.ac.uk/penta/ or accessed via the CHIVA website.
Infants born to HIV positive women

The book does have a good review of the history and methods of preventing mother to child transmission of HIV. This provides excellent background to this topic. However more practical information for managing these babies is provided in the British HIV Association (BHIVA) pregnancy guidelines, available at www.BHIVA.org.

I found the chapters on HIV in the central nervous system and gastrointestinal system very useful. I have already shared these with colleagues in child development centres and dieticians. Other organ specialists and members of the multidisciplinary team looking after children with HIV, would find other specific chapters helpful. The chapter on palliative care was particularly moving, encouraging those in this field to have humility and perseverance.

My main criticisms of the book were that it was too focussed on practice in the United States (not surprising when all the authors work there) and missed some recent developments. If a second edition is planned I hope it will include reference to the landmark HIV Paediatric Prognostic Markers Collaborative Study, ${ }^{1}$ recognise that the organism that causes PCP is now named Pneumocystis jiroveci (not $P$ carinii), and have some authors from outside the USA.

I would recommend that this book is available in every paediatric department who might see children with HIV. However it would be even more important for these units to have access to the guidelines on the CHIVA website and to have access to an expert in paediatric HIV. The establishment of managed clinical networks for paediatric HIV across the UK, as has already occurred in London, should improve this.

A Riordan

\section{Reference}

1 HIV Paediatric Prognostic Markers Collaborative Study Group. Short-term risk of disease progression in HIV-1-infected children receiving no antiretroviral therapy or zidovudine monotherapy: a meta-analysis. Lancet 2003;362:1605-11.

\section{CORRECTION}

doi: 10.1136/adc.2004.050468corr 1

I C K Wong, M L Murray, D Camilleri-Novak, et al. Increased prescribing trends of paediatric psychotropic medications (Arch Dis Child 2004;89:1131-2). The footnote for figure 1 in this short report was published incorrectly and should read "USA data is by ten thousand prescriptions". The authors apologise for the error.

\section{NOTICE}

doi: 10.1136/adc.2004.034785corr 1

\section{Competing interest statement}

Johnston LB, Savage MO. Should recombinant human growth hormone therapy be used in short small for gestational age children? Arch Dis Child 2004;89:740-4. The following statement accompanies this paper: Competing interests: Dr Pelton has acted as an expert witness regarding the outcome of bacterial meningitis during the last 5 years. 